
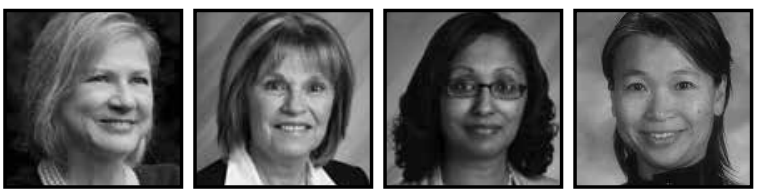

\title{
"Roots and Routes": Professional Educators' Transformative Insights Into the Linguistic and Experiential Worlds of Generation 1.5 Language Minority Students
}

Sandra R. Schecter, York University

Barbara Arthurs, Sherri Sengupta, and Alice Wong, York Region District School Board

\section{ABSTRACT}

This article explores findings of a project that addressed the academic literacy development of children who are born and/or begin their formal schooling in Canada, but who are raised in homes where the societally dominant language is not the primary idiom. It focuses on collaborating educators' professional learning through engagement in community-referenced action research that provided opportunities for eighth graders to explore themes related to their developing personal and socially situated identities. One key insight pertained to students' access to information regarding their family histories and trajectories; a second, to linguistic dynamics internal to generation 1.5 linguistic minority youths' households.

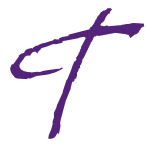

his article takes up findings of an action research project that focused on the academic literacy development of children who are born and/or begin their formal schooling in Canada, but who are raised in homes where the societally dominant language is not the primary idiom. While we elucidate key elements of a researcher-practitioner-community collaboration that had as its central goal to foster the school success of this student cohort, our main focus is on the lessons that we, as the students' teachers and mentors, learned-indeed, needed to learn-in the 
course of collaborative inquiry. These lessons were essential for us in comprehending and engaging with the issues that these youth confronted in negotiating academic expectations related to school-based learning, while navigating their personal and social worlds (Comber, 2013; Timperley \& Lee, 2008).

\section{Schooling Generation 1.5 Linguistic Minority Students}

We use the term generation 1.5 (G1.5) to refer to a demographic that comprises Canadian-born linguistic minority students as well as children born outside the country who start formal schooling, that is, kindergarten, in Canada. We have selected this term because the youth with whom our professional lives are intertwined share characteristics of both first-generation immigrants and second-generation children of immigrants (Rumbaut \& Ima, 1988). As such, these students do not fit into the traditional categories of non-native speakers since they are both orally proficient in English and reasonably familiar with Canadian culture and schooling (Roberge, 2002).

What do we know about the characteristics of generation 1.5 English language learners? Following Vasquez (2007), G1.5 students typically are initially identified by teachers as "highly engaged and motivated," and by the time it is evident that their classroom performance outcomes are insufficient to ensure academic success, it is often too late to intervene within the particular school year. From research at the tertiary (e.g., Roberge, 2002), secondary (e.g., Forrest, 2006), and primary (e.g., Schecter, 2012) levels, it is evident that these students have characteristics and needs distinct from both mainstream and immigrant language minority students (cf. Garnett, 2012).

We know that students who are born in North America or who arrive prior to beginning formal schooling may develop oral fluency in their heritage language, but typically have not had, and will not have, an opportunity to develop reading and writing skills in the home variety (e.g., Cummins, 1991; Schecter, 2012;' Wong Fillmore, 1991). These characteristics are significant in light of research evidence accumulated over the past 25 years that linguistic, cognitive, and affective advantages accrue to students who develop literacy skills in two or more languages and continue biliterate development at least through elementary school (see Corson, 1993, and Cummins \& Danesi, 1990, for reviews). Indeed, one of the most consistent findings in the literature on bilingualism is that literacy skills in the first (L1) and second (L2) language are strongly related. In other words, L1 and L2 literacy are interdependent, or manifestations of a common underlying proficiency. This interdependence principle 
is fundamental to understanding why literacy development in a minority language is not just promoting proficiency in that language; it is also promoting overall conceptual development and other forms of academic language that are transferable across languages (Cummins, 1996). By contrast, research has not produced sufficient evidence to support a hypothesis based on an "oral-written continuum." For example, Schecter and Bayley (2002) conducted an extensive study of language maintenance and cultural identification among Mexican-descent families in California and Texas, analyzing the oral and written narrative production of 40 focal children in Grades 4, 5, and 6-20 at each site-and found no correlation between the oral and written production of the focal children. On the contrary, they found that the children's language uses within these different modes represented distinct dimensions of language proficiency that are separable and situated in localized practices linked to the roles that English and Spanish played in the children's lives.

The preceding should not be taken as suggestive of a stance regarding "deficits" associated with particular child socialization practices or groups. Out-of-school literacies are not to be taken for granted with reference to any demographic grouping, including monolingual mainstream learners (cf. Lankshear, 1997). However, from sociolinguistic research (e.g., Bayley \& Schecter, 2003; Guerra, 1998) and from critiques emanating from the New Literacy Studies (e.g., Gregory, Williams, Baker, \& Street, 2004; Hull \& Schultz, 2002; Street, 2005), we understand well that learners' school literacy practices are culturally constructed, located both in power structure and in prior knowledge. We also know that prior knowledge is complex, and to build upon it productively we need to acknowledge that home background affects deep levels of identity and epistemology, including the stances that learners take toward calls to reading and writing in formal educational settings (Gough \& Bock, 2001; Lee, 2007; Street, 1997).

\section{Method: What We Did and How We Did It}

\section{Overview}

This project sought to: a) extend students' literacy repertoires through direct exposure to fields of experience; b) develop students' academic problem-solving skills; and c) provide pre-adolescent youths with opportunities to explore and develop their personal and socially situated identities. It revolved around a yearlong initiative comprising an interventionist curricular program that met once a week for two and a half hours during the regular school day. 
The study sought to ascertain: the types, and combinations, of approaches and activities that students, teachers, and other stakeholders considered helpful in fostering G1.5 language minority students' academic proficiency, and the role of activities that engaged youths in self-representational processes related to identity projection in promoting students' critical literacy and problem-solving abilities. The study's method involved a cyclical and recursive process (Boeije, 2010; Bogdan \& Biklen, 1998) of gathering and analyzing data related to students' academic problem solving and self representational processes, developing instructional formats and delivering instructional activities, identifying themes and categories, and sharing findings with students, educators, parents, and other engaged stakeholder groups. The study combined qualitative methodology that included intensive participant observation and ethnographic note taking, with some quantitative measures designed to process information on a large scale.

\section{Participants}

Participants included: 25 Grade 8 students, the majority aligning to the demographic under study (i.e., youths who were either born or began formal schooling in Canada, but who speak a language other than English in the home); the students' parents or caregivers; and the collaborating team, comprising university researcher Sandra Schecter, Grade 8 homeroom teacher Alice Wong, ESL Lead Resource Teacher Barbara Arthurs, and Randall Public School principal, Sherri Sengupta. While parents/ caregivers did not attend the instructional sessions, we consider them active participants since they interacted with members of the collaborating team and were present for school events at which team members elaborated project goals (in relation to the extant research on G1.5 language minority students) and presented study findings. As well, as will become apparent, parents played a catalytic role with regard to the identity work in which students engaged.

\section{Data Collection}

The lead author (at times also referred to as "Sandra" in this article) and the two participating teachers were responsible for designing the plans to facilitate each instructional session. To inform our analytic strands, we collected a variety of data types:

Field notes recorded by a member of the collaborating team as the session activities were ongoing tracked both the trajectory of the pedagogic framework that emerged from the project's action research agenda, as well as students' cognitive and social interactions with the curricular texts. In these close monitorings, we paid special 
attention to key moments and events associated with the learning and teaching processes that the activities generated.

Project activities were negotiated through postings on Google Docs. Generally, Sandra provided a draft session outline based on previous online or face-to-face discussion among the instructional team. Once a rudimentary plan was in place, we three then provided input to work out the details of the upcoming session. The process of making our thinking visible through these postings not only was helpful as we were getting to know one another and the students we were working with, but also allowed us to problem-solve around issues of logistics and sequence that arose from the plan. These exchanges were also helpful in making transparent the inconsistencies and gaps in our own assumptions regarding students' experiential repertoires and linguistic resources.

Notes on collaborative team meetings taken by the first author provided opportunities for increased understandings of the issues confronting G1.5 linguistic minority youth and for triangulating findings contained in the observational data related to instructional interventions.

Survey protocols and informal conversations with participating students before and after sessions elicited information on: family demographics, including ages of siblings and other household residents, parental levels of education and vocations, length of residence in Ontario for all family members; parents' orientations toward linguistic and/or cultural maintenance; students' language use patterns, including patterns of communication (i.e., who speaks what language to whom); students' orientations to previous and current educational experiences and more broadly related contextual issues.

Where project activities called on students to prepare oral presentations, submit written texts, or produce visual representations (e.g., maps), these artifacts were uploaded onto Google Drive. These texts were subsequently assembled into both student and activity portfolios. They constitute much of the pedagogical documentation on which observations leading to the professional learning outlined in the Findings section of this article are based.

Informal exchanges with parents/caregivers over activities initiated by the project, and other relevant aspects of family members' lives, provided valuable insights as well. 


\section{Data Analysis}

Two major strands of analysis were undertaken. One involved a process of: generating instructional protocols that showed promise in fostering G1.5 linguistic minority students' academic literacy development and problem-solving skills; documenting focal students' responses to these heuristics; and analyzing the understandings or impediments revealed in the debriefings that followed related activities. For this strand, rubrics were devised to elicit individual students' strategies in approaching different kinds of problem-solving tasks and to evaluate their receptivity to different meditational approaches; and comparisons were made across focal students. A second strand involved: in response to project developments, developing a series of heuristics that facilitated students' critical explorations of their evolving hybrid identities, and documenting students' orientations to, and engagements in, this identity work.

We are aware that the data sources for these two foci are not entirely separable; nor would we wish to impose artificial distinctions where such differentiations are not useful. Both foci involved youths in critical literacy activities designed to facilitate their engagements with tasks, protocols, and texts that they were likely to encounter as they negotiated the various demands of formal schooling. And, with both foci the information we were able to obtain regarding students' previous schooling, as well as their extra-school experiences, informed how we shaped and modified curricular interventions. The key contrast signaled in the differentiation of strands relates to analytic breadth, with the first focus attending more narrowly to strategy sequence and logical reasoning in relation to circumscribed problem-solving exercises, and the second focus, to the socially situated process involved in students reflecting on their experiences, beliefs, and other aspects of personal development, and projecting these understandings on their own identity representations (Gee, 2003; Zoss, Smagorinsky, \& O'Donnell-Allen, 2007). In this article, we privilege the insights we derived from the latter focus, that is, students' processes of identity representation and projection.

Transcriptions, written texts produced by students, observational notes, summaries, and other data were organized into tentative categories that recorded regularities and patterns (Bogdan \& Biklen, 1998). By iteratively examining, through a process of analytic induction, we were able to bring into focus the extent to which different instructional approaches were helpful in fostering the academic literacy development of these students and the various complex forces that informed the identity work of G1.5 linguistic minority youths. 


\section{"Roots and Routes": Collaborative Inquiry at Randall Public School}

In the remainder of this article we elucidate the community context of our initiative at Randall Public School, share examples of activities that brought together our cognitive and thematic agendas, and discuss the professional learning that resulted from our engagement in this collaborative undertaking. We begin by contextualizing our research through the following brief description of the Randall school community.

\section{The Randall Public School Community ${ }^{3}$}

Randall is a K-8 school located at the northern boundary of the Greater Toronto Area (GTA). In the fall of 2013 , the school population was 702 , with 560 , or $80 \%$, qualifying as English language learners (ELLs). Of these 560 ELL students, 493, or 88\%, were Canadian-born. In addition to English, the main languages spoken in the homes of Randall students, as identified by parents, were Urdu, Tamil, Punjabi, Cantonese, Mandarin, Gujarati, and Hindi. A majority of Randall students present to their teachers as native English speakers. Indeed, all but 4 of the 25 students in Ms. Wong's Grade 8 class did not have a marked dialect and were able to converse fluently in English.

Most Randall students do not engage in activities outside of school that involve "team" experiences (e.g., sports such as soccer, hockey, basketball), although many are enrolled in solitary enrichment activities (e.g., learning to play a musical instrument, tutoring classes). Randall teachers report the following pattern with regard to English language development among the ELL student cohort: "After making some progress in $\mathrm{JK} / \mathrm{K}$, they begin to stagnate, or plateau, and remain at a Stage 3 or 4 through Grades 2, 3, 4." ${ }^{\prime 4}$ By Grade 4 or 5, many of the Canadian-born ELL students are referred to an In School Team (IST) meeting for help with difficulties around speaking and writing with depth and elaboration.

Randall parents report that they speak their first language at home with their children, but their children respond in either English or a mixture of English and the parents' first language. Parents place a heavy emphasis on their child achieving high grades. However, most attest to difficulties in supporting their child academically, attributing this problem to their lack of familiarity with the Ontario school system, Ministry curricular expectations, and the ways in which subjects are taught and tasks are presented in Western schooling milieus (e.g., mathematical language or comprehensive approaches to literacy acquisition involving reading strategies and writing with supporting evidence). Moreover, they do not feel at ease with the role they are asked 
to play in supporting their child's learning (e.g., checking the student's homework or reading with their child a minimum of 20 minutes a day); and many default to traditional tutoring lessons often dispensed by teachers trained in their home country.

\section{Embarking on an Action Research Collaboration}

Strategic orientations. Cumulative evidence from the preliminary study suggested an interventionist project focused on developing G1.5 students' linguistic skills in tandem with their conceptual thinking, and combining three strategic orientations: A first orientation, which we call strategizing learning, focused on how learners think through a planning and/or problem-solving process. This component is represented by short exercises designed to build higher-order cognitive skills by making academic problem-solving strategies explicit (Feuerstein, Falik, \& Feuerstein, 2015; Feuerstein, 1990; Passow, 1980; Rohrer \& Pashler, 2010). A second orientation revolved around an experiential learning component, based on insights derived from "everyday concepts" acquired through exposure to experiences through activities supported by the project (Hedegaard, 1998; van Oers, 1998; Vygotsky, 1978). Examples of such activities included class trips to a waste management and recycling centre (see Figure 1), a farm, an art museum, a large urban produce market, and historical sites, as well as exposure through video to documentary footage about others' lives and circumstances.

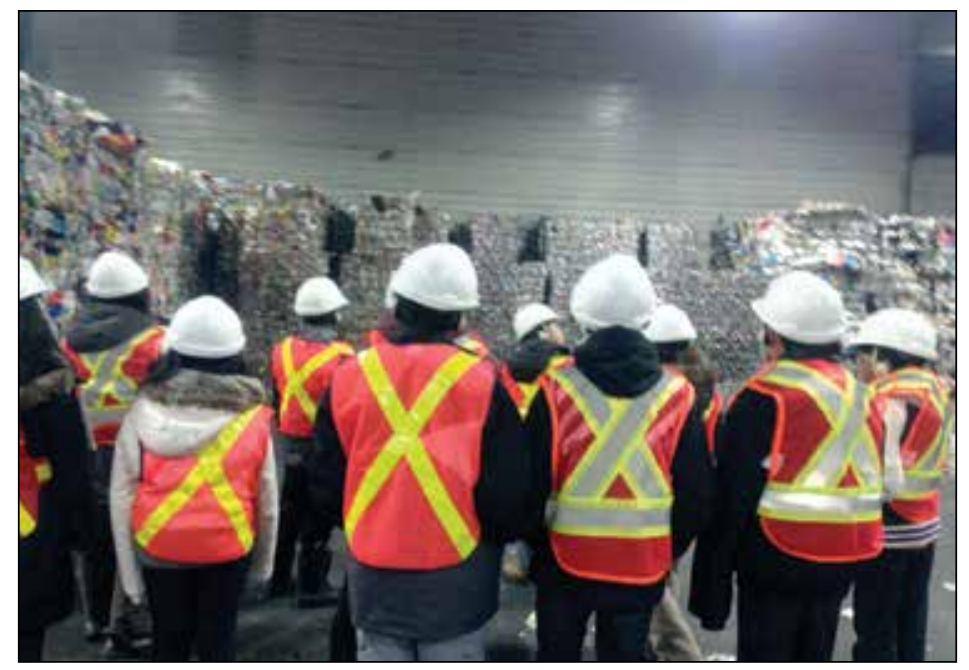

Fig. 1: A visit to York Region's Waste Management Centre 
For example, a field trip to the Art Gallery of Ontario fit well with the project's "blended identities" theme: in Figure 2 our students are seen discussing a painting titled, The Immigrants, by the Canadian artist Fred Varley. Following a guided tour of Euro-Canadian and First Nations art, our students, working in their cooperative groups, had the opportunity to create a cityscape sculpture in a workshop led by an in-residence artist. We found experiential learning to be a crucial component of our pedagogic agenda because, as van der Veer (1998) points out, academic learning presupposes everyday concepts as its foundation.

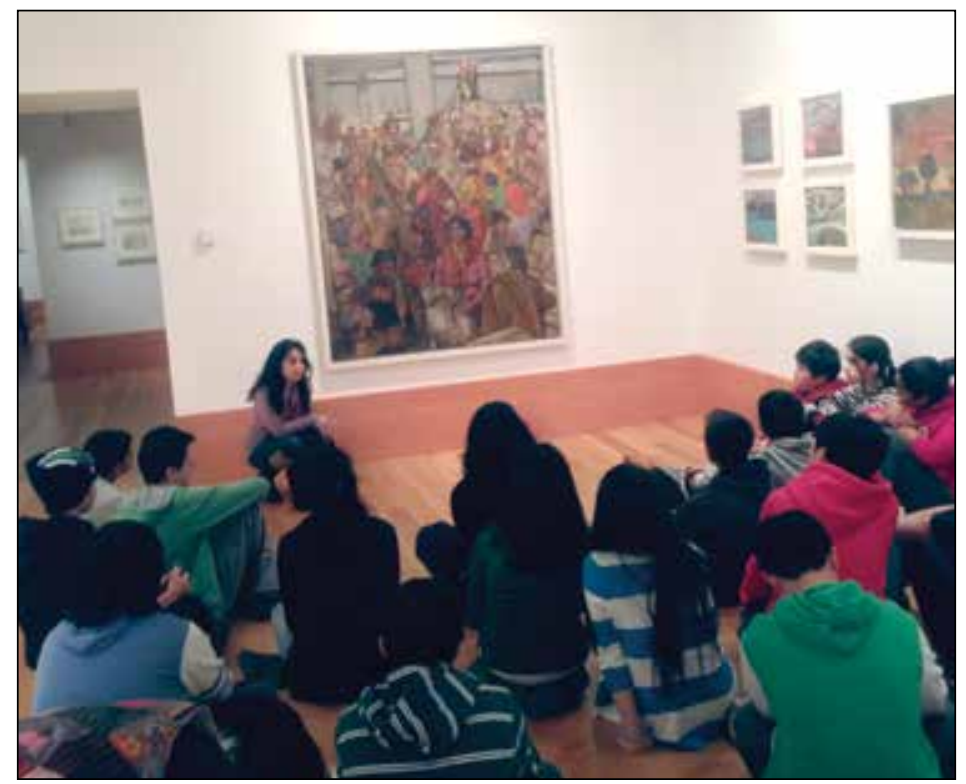

Fig. 2: Our students discussing the painting The Immigrants with AGO guide

A third, learning enrichment orientation was aimed at facilitating students' learning of academic subject matter concepts through bridging activities that involve applying concepts gleaned through experiential activities and related talk about language (Gibbons, 2003; Gutierrez, 1995; Toohey, 2000). Shortly after the inception of the project at Randall in fall 2014, the team elected to add a fourth strategic orientation to our action research agenda: each session would incorporate principles of cooperative learning, in that to accomplish the activity's objectives, students would work together collaboratively, drawing on one another's experiences and knowledge. 
Content and organization. In face-to-face and email discussions the preceding spring and summer, collaborators honed in on the content, or subject matter, of the pedagogical project-a series of cognitively challenging enrichment activities (cf. Gibbons, 2009), loosely following the Grade 8 Ontario curriculum, that allowed students to explore themes related to their developing personal and socially situated identities. We titled the project, "Roots and routes: Our blended identities," to signal the importance that Randall educators place on creating vehicles for students to both maintain their linguistic and cultural heritage and thrive in their New World environment (cf. Patel, 2006; Plaza, 2006). At the start of the academic year 2013-14, letters went home to caregivers of students enrolled in Ms. Wong's Grade 8 homeroom class explaining the goals of the "Roots and Routes" project and soliciting their permission for their child to participate. All caregivers responded positively to the informed consent exercise.

Focused on the theme of identity-or, more precisely, the complex identity work that students have to do to both maintain their linguistic and cultural heritage and negotiate a bicultural identity that would allow them to adapt to Canadian societyproject sessions were organized around themes relating to identity reconciliation that moved outward from the individual, to the family, to the school, and finally to the community. Sessions ranged from two hours to half a day in length. They were scheduled once a week throughout the school year, with gaps during holiday times or intensive work periods for students and teachers.

For example, a session constructed around the theme of "community" might begin with a short (10-minute) problem-solving exercise, or "Brain Teaser," where students are shown a grouping of cut trees lying on the ground and asked to determine the order in which the trees were cut down. This independent work would be followed by a teacher-led class discussion of the solution, in turn followed by a debriefing session in which students would volunteer the strategies they followed in attempting to solve the problem. Transitioning to an experiential component related to the same theme, students would then view the documentary film, Wasteland, where Vic Munoz, a successful artist, returns to Rio de Janeiro in his homeland of Brazil and works closely and collaboratively with some people he meets at the world's largest landfill. These are the workers, both men and women, who wade into the garbage heaps each day picking recyclable materials, labour for which they receive scant recompense. At the end of the session, students might assemble in their cooperative groups to engage in discussion about the film. This discussion represents a mediated learning activity in that it provides opportunities for students to become comfortable with representing the knowledge and insights that they have gleaned through watching the film (experiential learning) 
in the form of literate talk that is recognized as academic subject matter in the Ontario curriculum.

\section{Our Observations and What They Taught Us}

In keeping with the project's thematic emphasis on "blended" identities, in the fall of 2014 we asked students to trace the routes that their families had followed to arrive in Markham, and, more importantly, to record and construct a narrative around these life-altering journeys. The activities and sequencing of activities that we integrated into the unit, which ran over a period of approximately one month, reflected collaborating educators' familiarity with the research on the benefits of multimodal approaches to curriculum (Rowsell, 2012) - recitation, visual arts, written language-where students become acculturated to operating within new learning spaces (Kress, 2002).

Working in small groups, students were first asked to brainstorm interview questions that they might ask to elicit needed information from their primary caregivers, generally their parents. Through large-group discussion, these questions were then distilled into a single, comprehensive "survey" protocol that all students would use to interview family members. In the course of this guided discussion, students discussed the importance of integrating different kinds of questions-closed- and open-ended, factual and opinion-and reviewed the merits of different suggestions for incorporating strategies that could make an interview run more smoothly, for example, asking follow-up, or probe, questions if they needed more details related to a given response.

Using computers, iPhones, and iPads (some donated by the project, some by the collaborating board, and some by participating families), students audio recorded and subsequently transcribed their family members' stories, then created a map (or several maps) to show their parents' migration routes (Figure 3). 


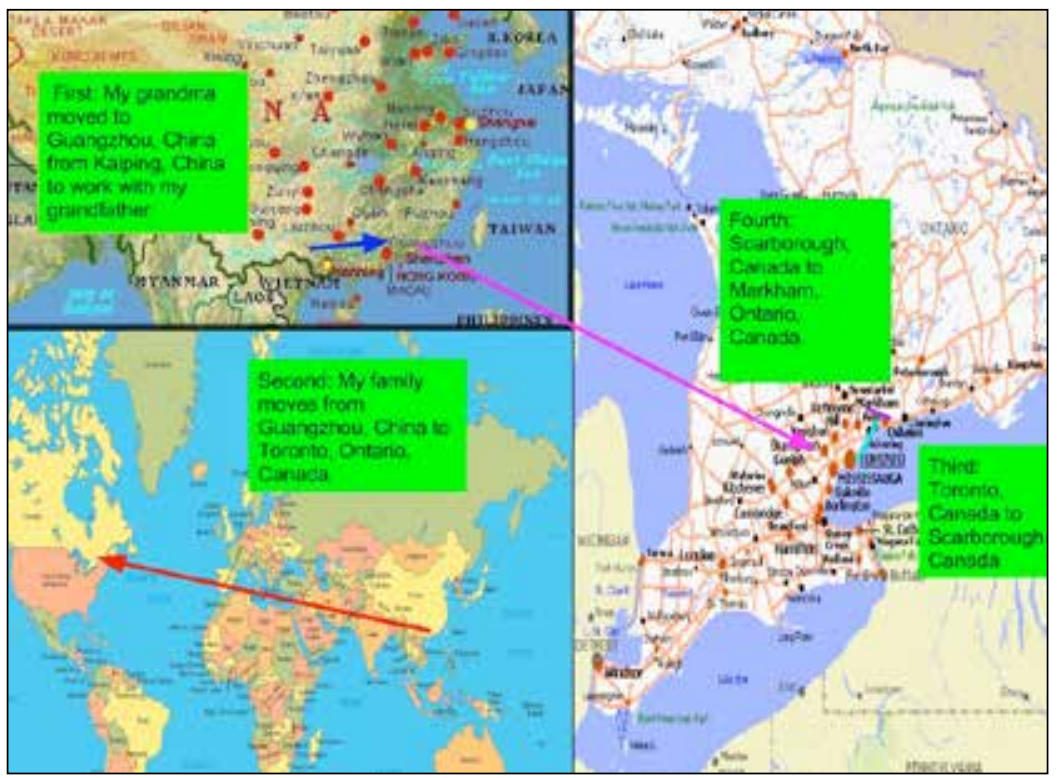

Fig. 3: Migration maps for June's family

We were careful to ensure that all students were familiar with, and had genuine access to, the technology they would need to complete key aspects of the activities. As the assignment was time-consuming, we gave the cohort ample time (two weeks) to complete their research. When the cohort regrouped, they shared the migration narratives they had elicited from their caregivers, first in partners, then in working groups, and finally with the whole cohort (with the last performance designated optional). In a subsequent session, we mapped each family's migration trajectory, not using pre-established maps, but rather gigantic butcher paper that students could physically jump onto to draw the different locales using different coloured markers (Figure 4). 


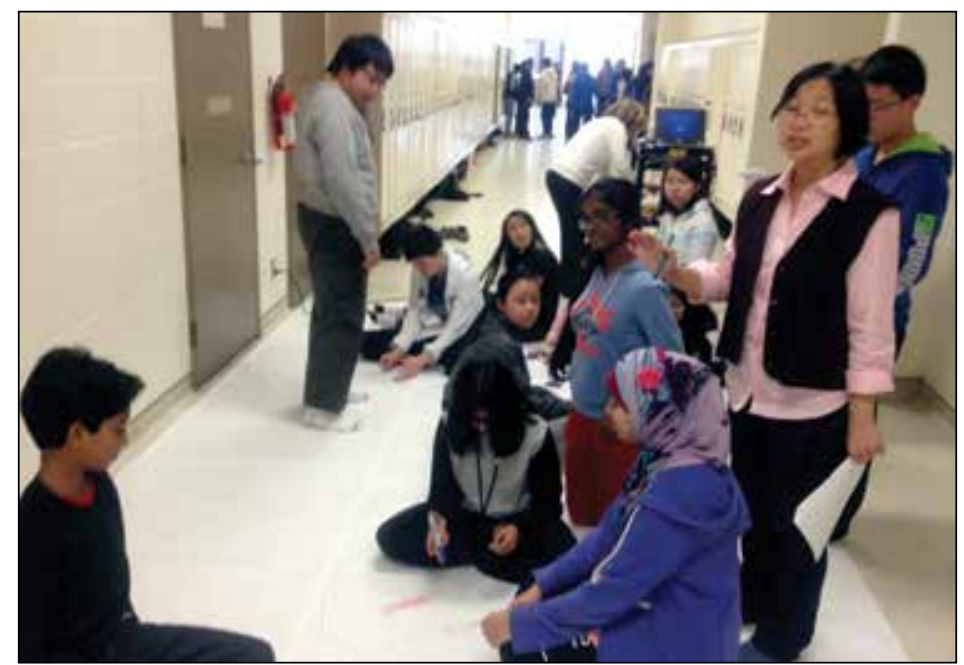

Fig. 4: Grade 8 students construct world map in the corridors of Randall Public School

On paper covering a good portion of the second floor of the school, students drew first the locations where they were born, and then the countries and regions where their parents were born. (Relative locations were problem-solved through discussion.) Students then went on to draw the different locations whence their parents had emigrated. Finally, they identified and located a country that they wished to visit in the future.

\section{"I Gave My Parents Some Space to Recollect Their Thoughts": Past Lives as New Knowledge}

During the two weeks when students were working on their own (with individualized assistance from one of us when needed), about a half dozen of the cohort's parents approached one of the authors to inquire about the goals of the project and, in particular, the purpose of the interview activity for which their cooperation was being enlisted. There appeared to be two sets of concerns. First, caregivers were apprehensive about issues of confidentiality, and needed to be reassured (even though the informed consent protocol that they had signed contained such an assurance) that the information they provided to their child would travel no further than the project and its dissemination agenda. Second, parents expressed confusion about the benefits that would accrue to their child by having access to information about their family history. 
In each instance, the answer we provided appeared to be satisfactory, given that caregivers' consent for their child's participation in the project was not withdrawn and parents' enthusiasm for the project grew over time. However, we noted with some interest that our initial explanations-focusing on the bridging of experiential and school-based learning that the unit's activities afforded and that research had shown was beneficial for the youths' academic literacy development-did not always prove sufficient. Caregivers seemed more compelled by a rationale about why access to their family's historical reenactments might represent an important exercise in selfdiscovery for youths who were not in a position to have shared first-hand in their elders' experiences of loss and recovery.

In the debriefings following the sessions that included oral sharings among cooperative group members and the larger group of the interview narratives and mapping activities, students overwhelmingly reported discovering aspects about their elders' pasts that they hadn't known before. This information concerned a variety of topics - details of courtships ("I was kind of surprised that my dad impress my grandma with some flower and turkey leg and ask for my mom in marriage"), past avocations ("I never knew that my dad owned an ice cream store...in India"), and notable achievements ("Another thing that was really interesting is that my dad was a sport champion back home in soccer and cricket!"). Note the sheer quantity of new knowledge about family members' past lives Hiten is attempting to assimilate in this posting:

I learned new things about my family's background. I learned that my dad was raised on a farm, and that he was a salesman. I also learned that he has 8 siblings. From my mom's side I also learned that her parents were divorced, and that her mother had to sell door to door to provide for her family...I think the most shocking information was that my mother's parents were divorced, and that her family was running on fumes so to speak.

Most of our students had no idea where family members had lived before arriving at their current place of residence, as noted in the following written observation:

I did not know that my grandparents were from this certain part of China because no one has actually informed me before about it. I always assumed it was just somewhere in the middle of China so I never asked. Also I did not know that when my dad landed in Canada that he did not live in Toronto, but Edmonton because I would have never expected him to live there. 
Not unexpectedly, students also discovered information about circumstances and events of a more sensitive nature. In the following extended excerpt, Mithika comes to terms with the recognition that her parents' formative years were very different from her own, as well as with the lingering effects of these early traumas:

Before I took the interview I always thought that my parents had a similar childhood to mine where they would go to school, hang out with friends and have a carefree childhood like every other child should have. However, my predictions were off when I learned that my parents lived most of their childhood in fear in not knowing when bombs would strike. They saw things that no child should see but in video games and experienced the fear of being in the middle of a flaming war. They never got a proper childhood in which they regret to never have experienced. They are upset that their childhood was too short and that they grew up too quickly to enjoy the life of a carefree child. Even today, they long to turn back time and have a proper childhood with no nightmares and no war.

A piece of information that I was surprised [by] the most was when my parents told me their age upon arrival to Canada. My mother was twenty-one and my father was only seventeen when he left Sri Lanka. When I hear these ages I can't bear to think how lonely and homesick they were to come to brand new country where you know no one and you are in a vast land with no guidance from your parents... learned that it has been over twenty-two years since my mom saw her parents face to face. This breaks my heart to not being able to see my parents for so long.

Perhaps as thought provoking for our students as revelations of harrowing events were cryptic references to biographical episodes, the full significance of which would likely never be revealed. Vincent, whose parents emigrated from China shortly before he was born, observed in his initial posting: "What surprised me the most was my grandfather's job. My mother told me that [her] father, my grandfather, was an interrogator for the government." During the cooperative group discussions, as Sandra left the classroom to prepare for the corridor-mapping activity, Vincent followed her out and, helping her tape butcher paper to the floor, asked what she thought the work of an interrogator was. "Probably to get information that the government or the authorities want to know," she responded, to which Vincent, dropping his characteristic bravado, rejoined, "Do they hurt people?" Sandra answered that she did not know and asked Vincent whether he would be all right with not knowing. "I don't need to know everything. I know stuff happened." 


\section{Linguistic Continuities and Discontinuities in G1.5 Students' Households}

A second, provocative insight that we acquired from our involvement in the "Roots and Routes" project revolved around the linguistic dynamics that were internal to generation 1.5 linguistic minority youths' households as family members negotiated the various dimensions of their cohabitation. At a basic level, we learned about the different languages that our students had exposure to in their homes. The following is a typical example: In Xiang's household, the grandparents speak one dialect, Taishan; the parents speak Cantonese; and Xiang speaks mostly English. Needless to mention, the student experienced challenges in carrying out the interview with her parentsin transmitting the referential meanings of the survey questions, in transcribing her parents' responses, and in accurately translating those responses back into English. In the debriefings, many students echoed Xiang's descriptions of the linguistic challenges involved in completing different dimensions of the activities associated with the interviews:

"They needed help from me in the middle of the interview [which these parents attempted to do in English] to how to say a certain word or sentence."

"I used a lot of time for the transcription process because I was unable to understand some things that my parents said. This is because my Mandarin is not very good."

"It was hard to translate the questions since I'm bad at Chinese and I don't know how to translate some of the words, so it was hard for them to understand me... and sometime misunderstood what I meant."

To overcome difficulties associated with the interview and mapping activities, students used a variety of problem-solving strategies to negotiate comprehensible input with their interlocutors:

"I went on Google Translate and typed out the question. As I showed it to them, I also tried to explain with gestures and pictures."

"I used an electronic dictionary to communicate with my mom...I also used examples so she could understand better." [In translating parents' responses from Guajarati into English]: "I try to cut sentences a bit shorter but still have the gist of it."

"I dealt with the problem by translating the questions into Tamil since it's his mother tongue and then onwards while transcripting the interview, I translated the Tamil 
into English. If the sentences didn't make sense I would have just fixed up a bit with my own words yet keeping the main and important ideas that were mentioned by my dad."

"When I had difficulty understanding ... my parents, I would let Ms. Wong listen to the recording. My teacher would then tell me what my parents said."

While collaborating educators did not find any of these problem-solving strategies surprising (the project placed considerable emphasis on resourcefulness), it did strike us in the course of the debriefings and subsequent data analysis that the different oral and textual negotiations associated with achieving accuracy in conveying and interpreting meaning for the purposes of the interview and mapping activities were not part of normal intrafamily routines for the majority of students. Zaiba's remark captured this phenomenon for the cohort, "I don't usually have to translate [in my home]. They [parents and grandparents] speak in Arabic, I speak in English."

While it is not the main goal of this article to analyze the linguistic dynamics that characterize G1.5 linguistic minority students' home environments, given our findings we would briefly reference recent discussions within applied linguistics circles on the intrinsic nature of the language abilities that individuals display as they function within communication contexts and settings characterized by features associated with superdiversity (Blommaert, 2013; Vertovec 2007, 2010) and plurilingualism (Little, Leung, \&Van Avermaet, 2013). Within these contexts, individuals have been found to call upon multiple linguistic repertories as they "cross borders either physically or virtually" (Garcia, 2009, p. 54).

Clearly, from information volunteered by our students, only a minority of youths involved in our project engaged in code-switching practices, where speakers who are fluent in more than one variety alternate between (generally) two codes or languages within a single conversation, alternately displaying the phonology and syntax consistent with each (e.g., Poplack, 1980; Zentella, 1998). Rather, the information we obtained makes a stronger case for a sociolinguistic phenomenon referred to as translanguaging (Garcia, 2009), where speakers' language activities cut across different semiotic systems previously considered separate, resulting in the generation of new meanings (e.g., Garcia \& Wei, 2013). However, for such translanguaging practices to represent viable systems for communication, we would need to see evidence of flexible, simultaneous uses of different linguistic forms and modalities in ways that maximize communicative potential among family interactants. We are in no way convinced that the data we have elicited point to that condition in relation to these generation 1.5 language minority students, ${ }^{5}$ although our student collaborators are clearly more dexterous with hybrid 
language practices than their caregivers (Garcia, 2009). To be sure, the integration of home languages into the class curriculum - a strategy that all four authors support ideologically-proved a more daunting challenge for our collaborating team than we initially anticipated. Indeed, for many G1.5 students linguistic maintenance would at this point entail the teaching and learning of the minority language as a second, not a native, variety. This said, we are grateful that we found a route to a strategy that created an interest among language minority students for pursuing practices of linguistic and cultural maintenance in future; and we even would be so bold as to suggest this, that is, starting with historical/biographical reconstruction in the service of identity representation, as a pedagogical approach going forward.

\section{Reflections on What We Learned That We Did Not Wholly Appreciate Before}

In summary, the aim of our project was to identify and pursue pedagogical approaches that showed promise in fostering the academic success and identity reconciliation of this particular student demographic. Grounded in the research of communityreferenced pedagogy (e.g., Schecter \& Ippolito, 2008; Schecter \& Sherri, 2009), it looked toward those techniques and those strategies that could be harnessed to individuals' prior knowledge and experiences as approaches that would hold the maximum potential for stimulating students' literate engagement (cf. Cummins \& Schecter, 2003). Given these philosophical tenets, the co-authors were enthusiastic about the potential of contemporary reenactments of students' family histories and trajectories to offer learning opportunities for linguistic and ethnic minority youth. We were also motivated to pursue this strategy by the knowledge that, as teachers, we would learn a great deal about our students - their family histories and the experiences that shaped their elders' perspectives.

However, the truly transformative dimension of our professional learning had to do with uprooting the core assumptions that we held about our students' access to key elements of their hybrid identities. We believed-on the basis of our previous experience, including research with immigrant, ESL learners (cf. Schecter \& Cummins, 2003) - that our students were already cognizant of information and events related to their family members' biographical histories. In that light, our role, in addition to academically mediating these archived experiences, was to facilitate access to resources and artifacts associated with their New World environment-a trip to the 
Art Gallery of Ontario to view the Group of Seven paintings and First Nations art, a visit to the St. Lawrence food market. We did not anticipate the elusive status of this biographical material and the cursory nature of students' prior encounters with family members' pasts.

Of course, such trajectories are recoverable; and certainly by the spring of 2014 participating caregivers were most appreciative that the project provided a venue for youths to explore the different historical forces, family circumstances, and serendipities that constituted their complex personal histories. However, in contrast to immigrant ESL students who by and large share in their parents' migration narratives, generation 1.5 language minority students' awareness of such critical events and circumstances cannot be taken for granted. Indeed, as facilitators we needed to appreciate that there are integral aspects related to these students' backgrounds that were not immediately (or even easily) accessible to them. For this work to proceed, and for our students to develop integrated hybrid identities, their elders needed to remember-the stereotypic courtships, the uprootings and regroundings, the livelihoods abandoned and reconstituted, and yes, the traumatic and disruptive events that, in Mithika's words, break your heart. For surely it is through these recollections that we come to understand ourselves, our relationships with others, and the kind of world we wish to live in.

Finally, given our insights regarding the sociolinguistic landscapes that generation 1.5 language minority students inhabit, we would be remiss if we did not observe that the multifarious ruptures referenced in caregivers' narratives have resulted in discontinuities with regard to language transmission that inevitably complicate social arrangements among these youths and their family members. In general, negotiating a common linguistic code in which to conduct family business proved more challenging than we initially anticipated, or than the research literature on socialization within linguistic minority homes (to which the lead author has contributed extensively; cf. Schecter \& Bayley, 2002) might suggest. In the end, given-not insurmountable, but compounding-circumstances relating to communication in families where members do not share access to a common linguistic code, the recollections of elders, stored in conscious and semiconscious crevices of narrative and visual memory, may well constitute the most powerful ties that connect our students to, and allow them to build academically on, the troves of knowledge associated with individuals and worlds left behind. 


\section{Authors' Note}

This project was supported by SSHRC Insight Development Grant 430-2011-0579 to the first author. The authors wish to thank Karine Rashkovsky and Yonah Atari for assistance with curriculum design, data collection, and analysis. We also express our deepest gratitude to the students and parents of Ms. Wong's Grade 8 class who participated in our project and trusted us with their stories.

\section{Notes}

1. In preparing for an interventionist project of a collaborative nature, the first author conducted a preliminary study in a different school that investigated how 10- to 12-year-old G1.5 linguistic minority students' formative experiences with languages predisposed their approaches to the processing of academic content and the performance of school literacy activities. She researched how junior-middle-school students used language in the home and community, including their patterns of language dominance, while simultaneously examining the students' reading and writing practices in response to school-based curriculum. See Schecter, 2012, for extensive discussion of the preliminary study's findings that significantly informed the design of our project at Randall.

2. We were introduced to the phrase roots and routes by our colleague Dan Yon at York University who suggested the following attribution: Gilroy, P. (1995). Roots and routes: Black identity as an outernational project. In H. W. Harris, H. C. Blue, \& E. H. Griffith (Eds.), Racial and ethnic identity: Psychological development and creative expression (pp. 15-30). London, England: Routledge.

3. Material for the section on the Randall community is based on information collected by Principal Sherri Sengupta in Fall 2013.

4. The stage descriptors used by Randall teachers in this quote reference the Ontario Ministry of Education's Second Language Acquisition and Literacy Development rubric. Students at Stage 3 demonstrate that they are able to use English independently in most contexts, while those at Stage 4 use English with a proficiency approaching that of a first-language speaker. The Ontario Ministry of Education is in the process of transitioning to a Steps to English Proficiency (STEP) framework 
for assessing and monitoring English Language Learners' language acquisition and literacy development across the Ontario curriculum. However, at the time of writing, the Stage framework is still in use in the York Region District School Board.

5. Indeed, in reviewing a draft of this article, Ms. Wong commented that the linguistic analysis helped to explain the frequent "miscommunications and misunderstandings between students and their parents/grandparents and other immediate family members" that she noted in facilitating the shunting of information back and forth from school to households.

\section{References}

Bayley, R., \& Schecter, S. R. (Eds.) (2003). Language socialization in bilingual and multilingual societies. Clevedon, England: Multilingual Matters.

Blommaert, J. (2013). Ethnography, superdiversity and linguistic landscapes: Chronicles of complexity. Clevedon, England: Multilingual Matters.

Boeije, H. (2010). Analysis in qualitative research. Los Angeles: Sage.

Bogdan, R., \& Biklen, S. (1998). Qualitative research for education. Boston: Allyn and Bacon, Inc.

Comber, B. (2013). Teachers as researchers: A "fair dinkum" learning legacy. English in Australia, 48(3), 54-61.

Corson, D. (1993). Language, minority education and gender: Linking social justice and power. Clevedon, England: Multilingual Matters.

Cummins, J. (1991). The development of bilingual proficiency from home to school: A longitudinal study of Portuguese-speaking children. Journal of Education, 173, 85-98.

Cummins, J. (1996). Negotiating identities: Education for empowerment in a diverse society. Los Angeles: California Association for Bilingual Education.
Cummins, J., \& Danesi, M. (1990). Heritage languages: The development and denial of Canada's linguistic resources. Toronto, ON: Our Schools Our Selves/Garamond.

Cummins, J., \& Schecter, S. R. (2003). Introduction: School-based language policy in culturally diverse contexts. In S. R. Schecter \& J. Cummins (Eds.), Multilingual education in practice: Using diversity as a resource (pp. 1-16). Portsmouth, NH: Heinemann.

Feuerstein, R. (1990). The theory of structural cognitive modifiability. In B. Z. Presseisen, R. J. Stenberg, K. W. Fischer, C. C. Knight, \& R. Feuerstein (Eds.), Learning and thinking styles: Classroom interaction (pp. 68-134). Washington, DC: National Education Association.

Feuerstein, R., Falik, L., \& Feuerstein, R. S. (2015). Changing minds \& brains: The legacy of Reuven Feuerstein. New York: Teachers College Press.

Forrest, S. (2006). Three foci of an effective high school generation 1.5 literacy program. Journal of Adolescent \& Adult Literacy, 50(2), 106-112.

Garcia, O. (2009). Education, multilingualism and translanguaging in the 21st century. In T. Skutnabb-Kangas, Social justice through multilingual education (pp. 140-158). Bristol, England: Multilingual Matters. 
Garcia, O., \& Wei, L. (2013). Translanguaging: Language, bilingualism and education. Basingstoke, England: Palgrave Pivot.

Garnett, B. (2012). A critical review of the Canadian empirical literature: Documenting generation 1.5 's $\mathrm{K}-16$ trajectories. TESL Canada Journal, 29(6), 1-24.

Gee, J. P. (2003). What video games have to teach us about learning and literacy. New York: Palgrave: Macmillan.

Gibbons, P. (2003). Mediating language learning: Teacher interactions with ESL students in a content-based classroom. TESOL Quarterly, 37(2), 247-273.

Gibbons, P. (2009). English learners, academic literacy, and thinking: Learning in the challenge zone. Portsmouth, $\mathrm{NH}$ : Heinemann.

Gilroy, P. (1995). Roots and routes: Black identity as an outernational project. In H. W. Harris, H. C. Blue, \& E. H. Griffith (Eds.), Racial and ethnic identity: Psychological development and creative expression (pp. 15-30). London, England: Routledge.

Gough, D., \& Bock, Z. (2001). Alternative perspectives on orality, literacy and education: A view from South Africa. Journal of Multilingual and Multicultural Development, 22(2), 95-111.

Gregory, E., Williams, A., Baker, D., \& Street, B. (2004). Introducing literacy to four year olds: Creating classroom cultures in three schools. Journal of Early Childhood Literacy, 4(1), 85-107.

Guerra, J. (1998). Close to home: Oral and literate practices in a transnational Mexicano community. New York: Teachers College Press.

Gutierrez, K. D. (1995). Unpacking academic discourse. Discourse Processes, 19, 21-37.

Hedegaard, M. (1998). Situated learning and cognition: Theoretical learning and cognition. Mind, Culture, and Activity, 5(2), 114-126.

Hull, G., \& Schultz, K. (Eds.) (2002). School's out! New York: Teachers College Press.

Kress, G. (2002). Literacy in the new media age. London, England: Routledge.
Lankshear, C. (1997). Changing literacies. Buckingham, England: Open University Press.

Lee, C. (2007). Culture, literacy, and learning: Taking bloom in the midst of the whirlwind. New York: Teachers College Press.

Little, D., Leung, C., \& Van Avermaet, P. (Eds.) (2013). Managing diversity in education: Languages, policies, pedagogies. Clevedon, England: Multilingual Matters.

Passow, A. H. (1980). Instrumental enrichment: Redeveloping cognitive structure. Educational Forum, 44(4), 393-400.

Patel, D. (2006). The maple-neem nexus: Transnational links of South Asian Canadians. In V. Satzewich \& L. Wong (Eds.), Transnational identities and practices in Canada (pp. 150-163). Toronto, ON: University of Toronto Press.

Plaza, D. (2006). The construction of a segmented hybrid identity among one-anda-half-generation and second generation Indo-Caribbean and African Caribbean Canadians. Identity, 6(3), 207-229.

Poplack, S. (1980). "Sometimes I'll start a sentence in Spanish y termino en español": Toward a typology of codeswitching. Linguistics, 18, 581-618.

Roberge, M. (2002). California's 1.5 immigrants: What experiences, characteristics and needs do they bring to our English classes? CATESOL Journal, 14(1), 107-129.

Rohrer, D., \& Pashler, H. (2010). Recent research on human learning challenges conventional instructional strategies. Educational Researcher, 39(5), 406-412.

Rowsell, J. (2012). Artifactual English. In M. Grenfell, D. Bloome, C. Hardy, K. Pahl, J. Rowsell, B. Street (Eds.), Language, ethnography, and education (pp. 110-131). New York: Routledge.

Rumbaut, R. G., \& Ima, K. (1988). The adaptation of Southeast Asian refugee youth: A comparative study: Final report to the Office of Resettlement. San Diego, CA: San Diego State University. (ERIC Document Reproduction Service No. ED 299 372) 
Schecter, S. R. (2012). The predicament of generation 1.5 English language learners: Three disjunctures and a possible way forward. Canadian Journal of Education, 35(4), 308-340.

Schecter, S. R., \& Bayley, R. (2002). Language as cultural practice: Mexicanos en el norte. Hillsdale, NJ: Lawrence Erlbaum Associates.

Schecter, S. R., \& Cummins, J. (Eds.). (2003). Multilingual education in practice: Using diversity as a resource. Portsmouth, $\mathrm{NH}$ : Heinemann.

Schecter, S. R., \& Ippolito, J. (2008). Parent involvement AS education: Activist research in multilingual and multicultural urban schools. Journal of Curriculum and Pedagogy, 5(1), 163-183.

Schecter, S. R., \& Sherri, D. L. (2009). "Value Added?": Teachers' investments in and orientations toward parent involvement in education. Urban Education, 44(1), 59-87.

Street, B. (1997). The implications of the "New Literacy Studies" for literacy education. English in Education, 31(3), 45-59.

Street, B. (Ed.). (2005). Literacies across educational contexts: Mediating learning and teaching. Philadelphia: Caslon.

Timperley, H., \& Lee, A. (2008). Reframing teacher professional learning: An alternative policy approach to strengthening valued outcomes for diverse learners. Review of Research in Education, 32(1), 328-369.

Toohey, K. (2000). Learning English at school: Identity, social relations and classroom practice. Clevedon, England: Multilingual Matters. van der Veer, R. (1998). From concept attainment to knowledge formation. Mind, Culture, and Activity, 5(2), 89-94.

van Oers, B. (1998). The fallacy of decontextualization. Mind, Culture, and Activity, 5(2), 135-142.

Vasquez, C. (2007). Comments from the classroom: A case study of a generation 1.5 student in a university IEP and beyond. Canadian Modern Language Review, 63(3), 345-370.

Vertovec, S. (2007). Super-diversity and its implications. Ethics and Racial Studies, 29(6), 1024-1054.

Vertovec, S. (2010). Towards post-multiculturalism? Changing communities, contexts and conditions of diversity. International Social Science Journal, 199, 83-95.

Vygotsky, L. (1978). Mind in society: The development of higher psychological processes. Cambridge, MA: Harvard University Press.

Wong Fillmore, L. (1991). When learning a second language means losing the first. Early Childhood Research Quarterly, 6, 323-346.

Zentella, A. C. (1998). Multiple codes, multiple identities: Puerto Rican children in New York City. In S. M. Hoyle \& C. T. Adger (Eds.), Kids talk: Strategic language use in later childhood (pp. 95-112). Oxford, England: Oxford University Press.

Zoss, M., Smagorinsky, P., \& O'Donnell-Allen, C. (2007). Mask-making as representational process: The situated composition of an identity project in a Senior English class. International Journal of Education and the Arts, 8(10), 1-40. 


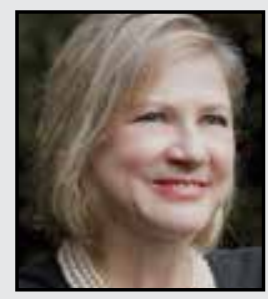

Sandra R. Schecter is professor of education and applied linguistics at York University. An ethnolinguist, she conducts research on language and literacy education and language planning in the context of bi- and multi-lingual societies. Her publications include the co-authored (with Jim Cummins) Multilingual Education in Practice: Using Diversity as a Resource (Heinemann) and the co-edited (with Lucinda Pease-Alvarez) volume Learning, Teaching and Community: Contributions of Situated and Participatory Approaches to Educational Innovation (Lawrence Erlbaum). Her collaboration with the York Region District School Board began serendipitously when she served with principal SenGupta on the Ontario Ministry of Education ELL Advisory Council (2010-2012).

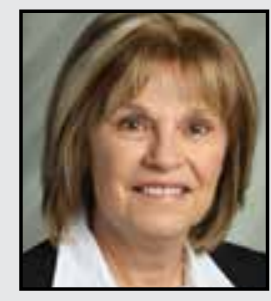

Barbara Arthurs is an elementary school teacher with the York Region District School Board. She has been an educator for the last 30 years, in a variety of teaching positions. For the past 13 years, Barbara has been working with English Language Learners in culturally diverse school environments. She has received ESL awards from the York Region District School Board $(2008,2013)$ for teaching excellence and innovation. Her professional learning has been much enhanced through participation as a member of a collaborating team with Dr. Schecter on this project involving G1.5 language minority students. 


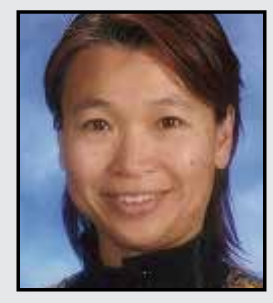

Alice Wong is an elementary school teacher with the York Region District School Board. In the past, she has worked as an adult ESL, literacy, and computing technology teacher, and has served as Literacy@School, Technology Lead, and Intermediate Lead Teacher at Randall Public School. She currently serves as Mathematics and Junior Lead Teacher at Reesor Park Public School, a position in which she promotes mathematics literacy and accountable math talk. An immigrant to Canada and speaker of English as a second language, she relates to the settlement and learning challenges her students and their families face on a daily basis.

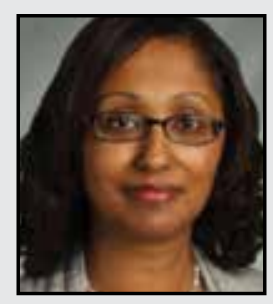

Sherri SenGupta is an elementary school Principal with the York Region District School Board. She has been an educator for the last 24 years, having devoted the majority of her professional time to promoting schooling environments that support English language learners. Her background and personal experiences as an ESL student have provided her with first-hand knowledge regarding the learning and social issues confronting English language learners. From 2010-2012 she served on the Ontario Ministry of Education ELL Advisory Council. She is thrilled and honoured to collaborate with Dr. Schecter on this ongoing project involving G1.5 language minority students.

\section{LINK TO:}

http://www.sandraschecter.com

http://mswonglearning.weebly.com 